\title{
The Use of microRNAs in the Management of Endometrial Cancer: A Meta-Analysis
}

\author{
Romain Delangle ${ }^{1,2, *}$, Tiphaine De Foucher ${ }^{3}$, Annette K. Larsen ${ }^{1,4}$, Michèle Sabbah ${ }^{1,4}$, \\ Henri Azaïs ${ }^{2}$, Sofiane Bendifallah 1,3, Emile Daraï 1,3, Marcos Ballester 5 , Céline Mehats 6 (D), \\ Catherine Uzan ${ }^{1,2,7}$ and Geoffroy Canlorbe ${ }^{1,2,7, *}$ \\ 1 Cancer Biology and Therapeutics, Centre de Recherche Saint-Antoine (CRSA), Sorbonne University, INSERM \\ UMR_S_938, 75020 Paris, France; annette.larsen@mfex.com (A.K.L.); michele.sabbah@inserm.fr (M.S.); \\ sofiane.bendifallah@aphp.fr (S.B.); emile.darai@aphp.fr (E.D.); catherine.uzan@aphp.fr (C.U.) \\ 2 Assistance Publique des Hôpitaux de Paris (AP-HP), Department of Gynecological and Breast Surgery and \\ Oncology, Pitié-Salpêtrière University Hospital, 75013 Paris, France; henri.azais@aphp.fr \\ 3 Assistance Publique des Hôpitaux de Paris (AP-HP), Department of Obstetrics and Gynaecology, \\ Tenon University Hospital, 75020 Paris, France; tiphainefc@hotmail.com \\ 4 Centre National de la Recherche Scientifique (CNRS), 75012 Paris, France \\ 5 Department of Gynecology, Groupe Hospitalier Diaconesses Croix Saint-Simon, 75020 Paris, France; \\ MBallester@hopital-dcss.org \\ 6 INSERM U1016-Institut Cochin, UMR 8104, Team “From Gametes to Birth”, University Paris Descartes, \\ 75014 Paris, France; celine.mehats@inserm.fr \\ 7 Institut Universitaire de Cancérologie (IUC), 75020 Paris, France \\ * Correspondence: romaindelangle@hotmail.fr (R.D.); geoffroy.canlorbe@aphp.fr (G.C.)
}

Received: 16 May 2019; Accepted: 11 June 2019; Published: 16 June 2019

\begin{abstract}
Introduction: Endometrial cancer (EC) is the most important gynecological cancer in terms of incidence. microRNAs (miRs), which are post-transcriptional regulators implicated in a variety of cellular functions including carcinogenesis, are particularly attractive candidates as biomarkers. Indeed, several studies have shown that the miR expression pattern appears to be associated with prognostic factors in EC. Our objective is to review the current knowledge of the role of miRs in carcinogenesis and tumor progression and their association with the prognosis of endometrial cancer. Materials and Method: We performed a literature search for miR expression in EC using MEDLINE, PubMed (the Internet portal of the National Library of Medicine) and The Cochrane Library, Cochrane databases "Cochrane Reviews" and "Clinical Trials" using the following keywords: microRNA, endometrial cancer, prognosis, diagnosis, lymph node, survival, plasma, FFPE (formalin-fixed, paraffin-embedded). The miRs were classified and presented according to their expression levels in cancer tissue in relation to different prognostic factors. Results: Data were collected from 74 original articles and 8 literature reviews which described the expression levels of $261 \mathrm{miRs}$ in ECs, including 133 onco-miRs, $110 \mathrm{miR}$ onco-suppressors, and $18 \mathrm{miRs}$ with discordant functions. The review identified 30 articles studying the expression pattern of miR in neoplastic endometrial tissue compared to benign and/or hyperplastic tissues, 12 articles detailing the expression profile of miRs as a function of lymph node status, and 14 articles that detailed the expression pattern of miRs in endometrial tumor tissue according to overall survival or in the absence of recurrence. Conclusions: The findings presented here suggest that miR analysis merits a role as a prognostic factor in the management of patients with endometrial cancer.
\end{abstract}

Keywords: endometrial cancer; microRNA; survival; nodal involvement; prognostic 


\section{Introduction}

Endometrial cancer (EC) is the most important gynecological cancer in terms of incidence with 380,000 new cases being diagnosed each year worldwide [1]. The most common histological type is endometrioid adenocarcinoma [2]. The current classification of endometrioid adenocarcinoma is based solely on histology which directs the subsequent therapeutic management [3]. However, this approach is often insufficient for prognosis. Therefore, the inclusion of additional criteria such as biological expression profiling will be needed to adapt both the surgical management and adjuvant therapy.

The molecular classification of endometrial cancer has revealed an important heterogeneity of tumors with comparable histological type and grade. Four molecular subtypes have been proposed, including (1) microsatellite instability hyper-mutated, (2) copy-number-low microsatellite stable, (3) copy-number-high serous-like, and (4) DNA polymerase epsilon (POLE) ultra-mutated. Histologically, this last group corresponds to endometrioid tumors [4].

Ongoing research aims to identify and characterize novel biomarkers for better understanding of the different subtypes, to provide improved assessment of prognosis, and for optimization of patient care. microRNAs (miRs) are particularly attractive candidates as biomarkers. miRs are post-transcriptional regulators that are implicated in a variety of cellular functions including carcinogenesis $[5,6]$ and resistance to treatment [7]. Typically, miRs display an RNA sequence complementary to the messenger RNA (mRNA) of a given gene, resulting in targeting and degradation of this mRNA, thereby leading to selective transcriptional repression [8]. However, a single miR may target several mRNAs and have either oncogenic or tumor suppressor activity depending on the tissue in which it is expressed $[5,6]$. Importantly, next-generation sequencing techniques can detect and quantify [9] the expression of miR in both fresh and paraffin-embedded tissues [10], as well as from liquid biopsies [11].

Regarding endometrial cancer, several studies have shown that the miR expression pattern appears to be associated with prognostic factors such as lymph node involvement [12-14], lymphovascular space invasion (LVSI) [15], overall survival [14,16-27] (OS), and recurrence-free survival (RFS) $[13,14,25,26]$.

Improved knowledge of the expression profile of miRs would likely explain certain molecular mechanisms associated with EC and could serve as a basis for diagnostic tests, prognosis, or the identification of potential novel therapeutic targets. To the best of our knowledge, there is no comprehensive recent review of the expression of miRs in EC. The objective of this review is to review the current knowledge of the role of miRNAs in carcinogenesis and tumor progression and their association with the prognosis of endometrial cancer.

\section{Materials and Methods}

A literature search for miR expression in EC was carried out using the following databases:

MEDLINE, PubMed (the Internet portal of the National Library of Medicine), http://www.ncbi. nlm.nih.gov/sites/entrez?db=pubmed.

The Cochrane Library, Cochrane databases "Cochrane Reviews" and "Clinical Trials". http: //www3.interscience.wiley.com/cgi-bin/mrwhome/106568753/HOMEDARE.

We used the following terms: microRNA, endometrial cancer, prognosis, diagnosis, lymph node involvement, survival, plasma, FFPE (formalin-fixed, paraffin-embedded).

The database search was further supplemented by using original articles, reviews, and meta-analyses, including the work cited within. Only articles published in English or French were included. The literature used was published between 1 November 2008 and 31 October 2018.

The miRs were classified and presented according to their expression levels in cancer tissue in relation to different prognostic factors. The expression profiles of the miRs according to lymph node status and survival were also explored. Finally, the relationship between the selected miRs in the plasma or serum and the presence of endometrial cancer is presented. 


\section{Results}

Data were collected from 75 original articles and 8 literature reviews published between 1 November 2008 and 31 October 2018 which described the expression levels of 261 miRs in ECs, including 133 onco-miRs, $110 \mathrm{miR}$ onco-suppressors, and $18 \mathrm{miRs}$ with discordant functions (miR-18b, $23 a^{*},-31,-34 a,-130 b,-142-3 p,-142-5 p,-146 a,-184,-185,-194,-200 c,-202,-204,-326,-432,-630,-760$ ) (Table S1).

\subsection{Expression Profile of miRs Associated with Malignant Endometrial Tissues Compared to Healthy or Hyperplastic Endometrial Tissues}

Our literature review identified 30 articles studying the expression pattern of miR in neoplastic endometrial tissue compared to in benign and/or hyperplastic tissues [13,14,23-25,28-52]. The studies included an average of 45 endometrial tumor samples (minimum 7, maximum 141), with well-defined histological types for 15 studies. The studies included an average of 18 healthy endometrial samples (minimum 5, maximum 48). The healthy endometrium was derived from operative specimens of patients operated on for benign pathologies, except for nine studies in which the healthy endometrium was taken from an area adjacent to the tumor.

miR extraction was carried out from paraffin or frozen tissue. For determination of the relative expression levels, on-chip hybridization techniques were used in ten studies and next-generation sequencing (NGS) was used in two studies, all validated by RT-qPCR. Compared to heathy endometrial tissues, endometrial tumors showed the following:

Increased expression of the following miRs: miR-9, -9*, -9-3p, -10a, -18a-3p, -19b, -25-5p, -27a, -31, -34a, -95, -96, -103, -106a, -106b, -107, -130b, -135a, -135b, -141, -142-5p, -146, -146b-5p, -151, -153, -155, $-181 a, 181 c-3 p,-181 c,-182,-183,-184,-191,-193-3 p,-194,-200 a,-200 a^{*},-200 a-5 p,-200 b,-200 b^{*},-200 c$, $-203,-205,-210,-215,-221,-223,-218,-301,-325,-326,-330,-337,-363,-423,-425,-429,-432,-449,-499$, $-518 d-5 p,-520 c-5 p,-522,-526 a,-1202,-5787$, and $-6749-5 p$.

Decreased expression of the following miRs: miR-10b, $-10 b^{*}-21,-23 a^{*},-29 c,-30 a-3 p,-30 a-5 p$, $-30 c,-31,-32,-33 b,-99 a,-99 a-3 p,-99 b,-100,-101,-126,-127-3 p,-133 b,-139-5 p,-152,-185,-193,-193 a$, $-193 b,-195,-196 a,-196 a-5 p,-199 b,-199 b-3 p,-199 b-5 p,-204,-214,-216 b,-221,-302 a-5 p,-328-3 p,-337-3 p$, $-338-3 p,-367-3 p,-368,-369,-370,-376 a,-376 c,-377,-377-5 p,-381,-409,-410,-411,-424,-424^{*},-424-3 p$, $-431,-432,-449 a,-451,-487 b,-496,-503,-516,-542-3 p,-542-5 p,-596,-610,-630,-632,-652,-758,-760$, and -1247 .

A summary of these data is provided in Table 1.

\subsection{Expression Profile of miRs According to Lymph Node Status}

Our literature review identified 12 articles detailing the expression profile of miRs as a function of lymph node status $[13,14,19,21,24-26,41,48,53-55]$.

The studies included an average of 11 samples with positive lymph node status (minimum 2, maximum 29) and 42 samples with negative lymph node status (minimum 13, maximum 121). Eight studies included only histological types.

Positive lymph node status was associated with increased expression of miR-10a, -10b, -26a, -26a1, $-34 a,-95,-123,-125 b 1,-125 b 2,-133 a,-143,-145 a,-181 a,-200 a^{*},-203,-222-3 p$, and -429 .

Positive lymph node status was also associated with decreased expression of miR $-24 b-5 p, 34 c-3 p$, $-34 c-5 p,-184,-204-5 p$, and 375.

A summary of these data is provided in Supplementary Table S2. 


\subsection{Expression Profile of miRs According to Survival}

Our literature review identified 14 articles that detailed the expression pattern of miRs in endometrial tumor tissue according to overall survival or in the absence of recurrence [13,14,16-27]. Five studies included only endometrioid carcinoma [14,18,20,24,27]. RNA extraction was predominantly carried out from paraffin-preserved tissue.

Significant improvement in overall survival was associated with the following:

Increased expression of miR-10b*, -29b, -100, -101, -129-2, -130b, -139-5p, -152, -183-5p, -194, $-199 a-5 p,-202$, and -455-5p;

Decreased expression of miR-200c, $-205,-429$, and -1228 and of the combined expression of six miRs (miR-15a, miR-142-3p, hsa-miR-142-5P, miR-3170, miR-1976, miR-146a).

Significant improvement in recurrence-free survival was associated with the following:

Increased expression of miR-29b, -152, -199a-5p, and -455-5p;

Decreased expression of miR-429 and -1228 .

A summary of these data is indicated in Table 2. 
Table 1. Differences in the expression profile of microRNAs (miRs) between malignant endometrial tissue and healthy endometrial tissue.

\begin{tabular}{|c|c|c|c|c|c|c|}
\hline Reference & Sample Type & Case Sample & Control Sample & $\begin{array}{l}\text { miR Increased } \\
\text { (Case vs. Control) }\end{array}$ & $\begin{array}{l}\text { miR Decreased } \\
\text { (Case vs. Control) }\end{array}$ & $\begin{array}{l}\text { Detection } \\
\text { Technique }\end{array}$ \\
\hline Liu Y. et al., 2018 [28] & - & $\begin{array}{l}\text { Endometrioid endometrial cancers } \\
(n=30): \\
15 \text { FIGO IA, } 15 \text { FIGO Ib }\end{array}$ & $\begin{array}{l}\text { Adjacent healthy } \\
\text { endometrial tissue }(n=30)\end{array}$ & - & $\operatorname{miR}-101$ & RT-qPCR \\
\hline Liu J. et al., 2018 [29] & & Endometrial cancers $(n=25)$ & $\begin{array}{l}\text { Endometrial tissue of } \\
\text { healthy cases }(n=15)\end{array}$ & - & miR-139-5p & RT-qPCR \\
\hline Ma J. et al., 2018 [30] & $\begin{array}{l}\text { Fresh Tissue, } \\
\text { Paraffin }\end{array}$ & Endometrial cancers $(n=80)$ & $\begin{array}{l}\text { Endometrial tissue of } \\
\text { healthy cases }(n=56)\end{array}$ & & $\begin{array}{l}\text { miR-302a-5p } \\
\text { miR-367-3p }\end{array}$ & RT-QPCR \\
\hline Huang et al., 2018 [31] & $-80^{\circ} \mathrm{C}$ & Endometrial cancers $(n=20)$ & $\begin{array}{l}\text { Endometrial tissue of } \\
\text { healthy cases }(n=20)\end{array}$ & miR-106b & - & $\begin{array}{l}\text { Array } \\
\text { RT-qPCR }\end{array}$ \\
\hline Fang et al., 2018 [51] & - & $\begin{array}{l}\text { Endometrial cancers }(n=69) \text { : } \\
33 \mathrm{~N}+ \\
36 \mathrm{~N}-\end{array}$ & $\begin{array}{l}\text { Endometrial tissue of } \\
\text { healthy cases }(n=10)\end{array}$ & $\begin{array}{l}\text { miR-182, miR-183, miR-153, } \\
\text { miR-27a, miR-96 }\end{array}$ & - & RT-qPCR \\
\hline Ushakov et al., 2018 [32] & - & $\begin{array}{l}\text { Endometrioid endometrial cancers } \\
\text { FIGO I-II }(n=32)\end{array}$ & $\begin{array}{l}\text { Adjacent healthy } \\
\text { endometrial tissue }(n=32)\end{array}$ & - & $\begin{array}{l}\text { miR-29c, miR-31, } \\
\text { miR-185, miR-652 }\end{array}$ & RT-qPCR \\
\hline Xie et al., 2017 [33] & Paraffin & $\begin{array}{l}\text { Endometrioid endometrial cancers } \\
(n=30): \\
12 \text { FIGO I, } 7 \text { FIGO II, } 11 \text { FIGO III } \\
15 \text { Grade 1, } 13 \text { Grade 2, } 2 \text { Grade } 3\end{array}$ & $\begin{array}{l}\text { Adjacent healthy } \\
\text { endometrial tissue }(n=30)\end{array}$ & - & $\mathrm{miR}-216 \mathrm{~b}$ & RT-qPCR \\
\hline Zhang S. et al., 2017 [34] & Paraffin & $\begin{array}{l}\text { Endometrial cancers ( } n=37): \\
21 \text { FIGO I, } 5 \text { FIGO II, } 4 \text { FIGO III } 5 \\
\text { FIGO IV' } \\
25 \text { Grade 1, } 7 \text { Grade 2, } 5 \text { Grade } 3\end{array}$ & $\begin{array}{l}\text { Endometrial tissue of } \\
\text { healthy cases }(n=22)\end{array}$ & - & miR-101 & RT-qPCR \\
\hline Chen et al., 2017 [35] & $-80^{\circ} \mathrm{C}$ & Endometrial cancers $(n=15)$ & $\begin{array}{l}\text { Hyperplasic endometrial } \\
\text { tissue }(n=15) \\
\text { Endometrial tissue of } \\
\text { healthy cases }(n=15)\end{array}$ & miR-5787, -6749-5p, -1202 & $\begin{array}{l}\text { miR-338-3p, } \\
\text { miR-449a, } \\
\text { miR-196a }\end{array}$ & $\begin{array}{l}\text { Array } \\
\text { RT-qPCR }\end{array}$ \\
\hline He et al., 2017 [36] & $\begin{array}{l}\text { Paraffin } \\
-80^{\circ} \mathrm{C}\end{array}$ & $\begin{array}{l}\text { Endometrial cancers }(n=68) \text { : } \\
54 \text { endometrioid, } 14 \text { others } \\
55 \text { FIGO I-II, } 13 \text { FIGO III-IV } \\
50 \text { Grade } 1-2,18 \text { Grade } 3 \\
59 \mathrm{~N}+, 9 \mathrm{~N}-\end{array}$ & $\begin{array}{l}\text { Endometrial tissue of } \\
\text { healthy cases }(n=20)\end{array}$ & miR-944 & - & RT-qPCR \\
\hline
\end{tabular}


Table 1. Cont

\begin{tabular}{|c|c|c|c|c|c|c|}
\hline Reference & Sample Type & Case Sample & Control Sample & $\begin{array}{c}\text { miR Increased } \\
\text { (Case vs. Control) }\end{array}$ & $\begin{array}{l}\text { miR Decreased } \\
\text { (Case vs. Control) }\end{array}$ & $\begin{array}{l}\text { Detection } \\
\text { Technique }\end{array}$ \\
\hline Wang Z. et al., 2017 [37] & - & Endometrial cancers & $\begin{array}{l}\text { Endometrial tissue of } \\
\text { healthy cases }(n=15)\end{array}$ & $\begin{array}{l}\text { miR-522, } \\
\text { miR-139-3p, } \\
\text { miR-520c-5p, } \\
\text { miR-518d-5p, } \\
\text { miR-146b-5p, } \\
\text { miR-34a, miR-526a, } \\
\text { miR-193a-3p, } \\
\text { miR-221, miR-4674 }\end{array}$ & $\operatorname{miR}-760$ & $\begin{array}{l}\text { Array } \\
\text { RT-qPCR }\end{array}$ \\
\hline Cai et al., 2016 [38] & $-80^{\circ} \mathrm{C}$ & Endometrial cancers $(n=24)$ & $\begin{array}{l}\text { Adjacent healthy } \\
\text { endometrial tissue }(n=24)\end{array}$ & miR-337 & - & RT-qPCR \\
\hline Zhao et al., 2016 [39] & $-70^{\circ} \mathrm{C}$ & Endometrial cancers $(n=11)$ & $\begin{array}{l}\text { Adjacent healthy } \\
\text { endometrial tissue }(n=11)\end{array}$ & - & miR-126 & RT-qPCR \\
\hline Yoneyama et al., 2015 [40] & Fresh Tissue & $\begin{array}{l}\text { Endometrioid endometrial cancers } \\
\text { I }(n=7) \text { : IA Grade } 1-2 \text {, IB Grade } \\
1-3, \text { IIIA Grade } 1 \text {, IIIC Grade } 2\end{array}$ & $\begin{array}{l}\text { Adjacent healthy } \\
\text { endometrial tissue }(n=7)\end{array}$ & miR-200a, $-200 b,-429$ & - & $\begin{array}{l}\text { Array } \\
\text { RT-qPCR }\end{array}$ \\
\hline He et al., 2015 [41] & Paraffin & $\begin{array}{l}\text { Endometrioid endometrial cancers } \\
(n=47) \text { : } \\
38 \text { FIGO I-II, } 9 \text { FIGO III-IV; } 32 \\
\text { Grade } 1,15 \text { Grade } 2-3 \\
42 \mathrm{~N}, 5 \mathrm{~N}+\end{array}$ & $\begin{array}{l}\text { Hyperplasic endometrial } \\
\text { tissue }(n=18), \\
\text { Endometrial tissue of } \\
\text { healthy cases }(n=13)\end{array}$ & miR-181a & - & RT-qPCR \\
\hline Kong et al., 2014 [42] & - & $\begin{array}{l}\text { Endometrioid endometrial cancers } \\
(n=21)\end{array}$ & $\begin{array}{l}\text { Endometrial tissue of } \\
\text { healthy cases }(n=14)\end{array}$ & - & $\mathrm{miR}-30 \mathrm{c}$ & RT-qPCR \\
\hline Jurcevic et al., 2014 [43] & Paraffin & $\begin{array}{l}\text { Endometrial cancers }(n=30): 10 \\
\text { FIGO I, } 10 \text { FIGO II, } 10 \text { FIGO III }\end{array}$ & $\begin{array}{l}\text { Endometrial tissue of } \\
\text { healthy cases }(n=20)\end{array}$ & $\begin{array}{l}\operatorname{miR}-183,-182,429,-135 a \\
-9-3 p,-9,135 b,-200 a-5 p \\
-218,-18 a-3 p\end{array}$ & $\begin{array}{l}\operatorname{miR}-1247,-199 b-5 p \\
-214,-370,-424-3 p \\
-376 c,-542-5 p,-758 \\
-377,337-5 p\end{array}$ & RT-qPCR \\
\hline Tsukamoto et al., 2014 [13] & - & $\begin{array}{l}\text { Endometrioid endometrial cancers } \\
(n=28): \\
4 \mathrm{~N}+, 21 \mathrm{~N}-\text {, } \\
7 \text { FIGO IA Grade } 1\end{array}$ & $\begin{array}{l}\text { Endometrial tissue of } \\
\text { healthy cases }(n=14)\end{array}$ & $\operatorname{miR}-499,-135 b,-205$ & $\begin{array}{l}\operatorname{miR}-10 b,-195 \\
-30 a-5 p,-30 a-3 p,-21\end{array}$ & $\begin{array}{l}\text { RNAseq } \\
\text { RT-qPCR }\end{array}$ \\
\hline
\end{tabular}


Table 1. Cont.

\begin{tabular}{|c|c|c|c|c|c|c|}
\hline Reference & Sample Type & Case Sample & Control Sample & $\begin{array}{c}\text { miR Increased } \\
\text { (Case vs. Control) }\end{array}$ & $\begin{array}{l}\text { miR Decreased } \\
\text { (Case vs. Control) }\end{array}$ & $\begin{array}{l}\text { Detection } \\
\text { Technique }\end{array}$ \\
\hline Xiong et al., 2014 [52] & $-80^{\circ} \mathrm{C}$ & $\begin{array}{l}\text { Endometrioid endometrial cancers } \\
(n=15)\end{array}$ & $\begin{array}{l}\text { Adjacent healthy } \\
\text { endometrial tissue }(n=15)\end{array}$ & $\begin{array}{l}\operatorname{miR}-181 c-3 p \\
-25-5 p\end{array}$ & $\begin{array}{l}\text { miR-99a-3p, -96a-5p, } \\
-328-3 p,-337-3 p \\
\text { let-7c-5p }\end{array}$ & $\begin{array}{l}\text { RNAseq } \\
\text { RT-qPCR }\end{array}$ \\
\hline Xu et al., 2013 [44] & $-80^{\circ} \mathrm{C}$ & $\begin{array}{l}\text { Endometrioid endometrial cancers } \\
(n=71)\end{array}$ & $\begin{array}{l}\text { Endometrial tissue of } \\
\text { healthy cases }(n=5) \\
\text { Adjacent healthy } \\
\text { endometrial tissue }(n=10) \\
\text { Hyperplasic endometrial } \\
\text { tissue }(n=9)\end{array}$ & - & miR-503 & RT-qPCR \\
\hline Torres et al., 2013 [14] & $\begin{array}{l}\text { Paraffin } \\
-80^{\circ} \mathrm{C}\end{array}$ & $\begin{array}{l}\text { Endometrioid endometrial cancers } \\
(n=77) \text { : } \\
50 \text { FIGO I, } 5 \text { FIGO II, } 20 \text { FIGO III, } 2 \\
\text { FIGO IV } \\
29 \text { Grade } 1,30 \text { Grade } 2,18 \text { Grade } 3 \\
29 \mathrm{~N}+, 15 \mathrm{~N}-\end{array}$ & $\begin{array}{l}\text { Endometrial tissue of } \\
\text { healthy cases }(n=31)\end{array}$ & $\begin{array}{l}\operatorname{miR}-9,-141,-183,-200 a \\
-200 a^{*},-200 b,-200 b^{*},-200 c \\
-203,-205,-429,-96,-182 \\
-135 b\end{array}$ & $\operatorname{miR}-410$ & $\begin{array}{l}\text { Array } \\
\text { RT-qPCR }\end{array}$ \\
\hline Torres et al., 2012 [24] & $\begin{array}{l}\text { Paraffin } \\
-80^{\circ} \mathrm{C}\end{array}$ & $\begin{array}{l}\text { Endometrioid endometrial cancers } \\
(n=77) \text { : } \\
50 \text { FIGO I, } 5 \text { FIGO II, } 20 \text { FIGO III, } 2 \\
\text { FIGO IV } \\
29 \text { Grade } 1,30 \text { Grade } 2,18 \text { Grade } 3 \\
29 \mathrm{~N}+, 15 \mathrm{~N}-\end{array}$ & $\begin{array}{l}\text { Endometrial tissue of } \\
\text { healthy cases }(n=31)\end{array}$ & - & miR-99a, $-100,-199 b$ & RT-qPCR \\
\hline Lee et al., 2012 [45] & Paraffin & $\begin{array}{l}\text { Endometrial cancers }(n=22): \\
15 \text { FIGO IA, } 5 \text { FIGO IB, } 2 \text { FIGO } \\
\text { IIIC1 }\end{array}$ & $\begin{array}{l}\text { Endometrial tissue of } \\
\text { healthy cases }(n=10) \\
\text { Hyperplasic endometrial } \\
\text { tissue }(n=21) \\
\text { Atypical hyperplasic } \\
\text { endometrial tissue }(n=22)\end{array}$ & $\begin{array}{l}\operatorname{miR}-182,-183,-200 a,-200 c, \\
-205\end{array}$ & - & RT-qPCR \\
\hline Karaayvaz et al., 2012 [23] & Paraffin & $\begin{array}{l}\text { Endometrial cancers ( } n=48) \text { : } \\
24 \text { endometrioid, } 13 \text { serous, } 5 \text { clear } \\
\text { cell, } 6 \text { others } \\
26 \text { FIGO I, } 4 \text { FIGO II, } 6 \text { FIGO III, } 12 \\
\text { FIGO IV }\end{array}$ & $\begin{array}{l}\text { Adjacent healthy } \\
\text { endometrial tissue }(n=48)\end{array}$ & $\begin{array}{l}\text { miR-200c } \\
\text { miR-205 }\end{array}$ & - & RT-qPCR \\
\hline
\end{tabular}


Table 1. Cont.

\begin{tabular}{|c|c|c|c|c|c|c|}
\hline Reference & Sample Type & Case Sample & Control Sample & $\begin{array}{c}\text { miR Increased } \\
\text { (Case vs. Control) }\end{array}$ & $\begin{array}{l}\text { miR Decreased } \\
\text { (Case vs. Control) }\end{array}$ & $\begin{array}{l}\text { Detection } \\
\text { Technique }\end{array}$ \\
\hline Snowdon et al., 2011 [46] & Paraffin & $\begin{array}{l}\text { Endometrioid endometrial cancers } \\
(n=19): \\
9 \text { FIGO IA, } 4 \text { FIGO IB, } 1 \text { FIGO II. }\end{array}$ & $\begin{array}{l}\text { Endometrial tissue of } \\
\text { healthy cases }(n=10) \\
\text { Atypical hyperplasic } \\
\text { endometrial tissue }(n=14)\end{array}$ & $\begin{array}{l}\mathrm{miR}-9 /-9^{*},-18 \mathrm{a},-96,-141 \\
-146 \mathrm{a},-200 \mathrm{a} / \mathrm{b} / \mathrm{b}^{*} / \mathrm{c},-203 \\
-205,-210,-421,-429 \\
-516 a-5 p,-605,-614,-936\end{array}$ & $\begin{array}{l}\mathrm{miR}-10 \mathrm{~b}^{*},-23 \mathrm{a}^{*},-100 \\
-127-3 \mathrm{p},-152, \\
-199 \mathrm{~b}-3 \mathrm{p},-199 \mathrm{~b}-5 \mathrm{p} \\
-370,376 \mathrm{a} / \mathrm{c},-381,-410 \\
-424,-424^{*},-431,-432 \\
-503,-542-3 / 5 p,-596 \\
610,630,632,760\end{array}$ & $\begin{array}{l}\text { Array } \\
\text { RT-qPCR }\end{array}$ \\
\hline Cohn et al., 2010 [25] & Paraffin & $\begin{array}{l}\text { Endometrial cancers ( } n=141): 121 \\
\text { endometrioid FIGO I ( } 90 \text { Grade 1, } \\
27 \text { Grade 2, } 4 \text { Grade 3), } \\
3 \text { endometrioid FIGO III, } \\
7 \text { serous FIGO III, } \\
4 \text { endometrioid FIGO IV } \\
6 \text { serous FIGO IV }\end{array}$ & $\begin{array}{l}\text { Endometrial tissue of } \\
\text { healthy cases: } \\
10 \text { pre-menopausal tissues } \\
10 \text { post-menopausal tissues }\end{array}$ & $\begin{array}{l}\mathrm{miR}-9,-19 \mathrm{~b} ;-146,-181 \mathrm{c} \\
-183,-200 \mathrm{c},-205,-223,-423 \\
-425\end{array}$ & $\begin{array}{l}\text { let-7a, miR-32, -33b, } \\
-369,-409,-424,-431 \\
-451,-496,-503,-516\end{array}$ & $\begin{array}{l}\text { Array } \\
\text { RT-qPCR }\end{array}$ \\
\hline Ratner et al., 2010 [47] & $\begin{array}{l}\text { Paraffin } \\
-80^{\circ} \mathrm{C}\end{array}$ & $\begin{array}{l}\text { Endometrial cancers }(n=90): 57 \\
\text { endometrioid ( } 27 \text { FIGO I, } 12 \text { FIGO } \\
\text { II, } 18 \text { FIGO III), } \\
27 \text { serous } \\
6 \text { carcinosarcoma. }\end{array}$ & $\begin{array}{l}\text { Endometrial tissue of } \\
\text { healthy cases }(n=5)\end{array}$ & $\begin{array}{l}\operatorname{miR}-182,-183,-200 a,-205 \\
-34 a,-572,-622,-650\end{array}$ & $\operatorname{miR}-411,-487 \mathrm{~b}$ & $\begin{array}{l}\text { Array } \\
\text { RT-qPCR }\end{array}$ \\
\hline Chung et al., 2009 [48] & $-80^{\circ} \mathrm{C}$ & $\begin{array}{l}\text { Endometrioid endometrial cancers } \\
(n=30): \\
25 \text { FIGO I-II, } 5 \text { FIGO III } \\
19 \text { Grade } 1,11 \text { Grade } 2 \\
3 \mathrm{~N}+, 27 \mathrm{~N}-\end{array}$ & $\begin{array}{l}\text { Endometrial tissue of } \\
\text { healthy cases }(n=22) \text { : } \\
7 \text { in proliferating phase } \\
7 \text { in the secretory phase } \\
8 \text { post-menopausal tissues }\end{array}$ & $\begin{array}{l}\text { miR-10a, }-17-5 p,-23 a^{*},-25 \\
-28,-34 a,-95,-103,-106 a \\
-107,-130 b,-141,-151,-155 \\
-182,-183,-184,-191,-194 \\
-200 a / c,-203,-205,-210,-215 \\
-223,-301,-325,-326,-330\end{array}$ & - & RT-qPCR \\
\hline Wu et al., 2009 [49] & $-80^{\circ} \mathrm{C}$ & $\begin{array}{l}\text { Endometrioid endometrial cancers } \\
(n=10) \text { : } \\
5 \text { FIGO I, } 5 \text { FIGO II }\end{array}$ & $\begin{array}{l}\text { Adjacent healthy } \\
\text { endometrial tissue }(n=10)\end{array}$ & $\begin{array}{l}\mathrm{miR}-200 \mathrm{c},-449,-205,-182 \\
-429,-200 \mathrm{~b},-96,-31,-141 \\
-200 \mathrm{a},-363,-210,-432,-203 \\
-10 \mathrm{a},-155,-142-5 p\end{array}$ & $\begin{array}{l}\operatorname{miR}-204,-193 a,-368 \\
-133 b,-193 b,-99 b\end{array}$ & $\begin{array}{l}\text { Array } \\
\text { RT-qPCR }\end{array}$ \\
\hline Boren et al., 2008 [50] & $-80^{\circ} \mathrm{C}$ & $\begin{array}{l}\text { Endometrioid endometrial cancers } \\
(n=37)\end{array}$ & $\begin{array}{l}\text { Endometrial tissue of } \\
\text { healthy cases }(n=20) \\
\text { Atypical hyperplasic } \\
\text { endometrial tissue }(n=4)\end{array}$ & $\begin{array}{l}\text { Let-7c, miR-103, }-106 a,-107, \\
-181 a,-185,-210,-423\end{array}$ & $\begin{array}{l}\text { let } 7 \mathrm{i}, \mathrm{miR}-30 \mathrm{c},-152 \text {, } \\
-193,-221\end{array}$ & $\begin{array}{l}\text { Puce } \\
\text { RT-qPCR }\end{array}$ \\
\hline
\end{tabular}

FIGO: International Federation of Gynecology and Obstetrics, N: ganglionic status, RT-qPCR: real-time quantitative polymerase chain reaction. 
Table 2. Expression profile of microRNAs within neoplastic endometrial tissue according to survival.

\begin{tabular}{|c|c|c|c|}
\hline Reference & $\begin{array}{l}\text { Sample } \\
\text { Type }\end{array}$ & Sample Case & Conclusion \\
\hline Wang Y. et al., 2018 [16] & - & Endometrial cancers $(n=348)$ & $\begin{array}{l}\text { The signature of } 6 \text { miRs (miR-15a, miR-142-3p, } \\
\text { hsa-miR-142-5P, miR-3170, miR-1976, miR-146a) is associated } \\
\text { with a significant decrease in OS } \\
\text { (HR }=0.446 ; 95 \% \text { CI: } 0.218-0.913)\end{array}$ \\
\hline Yan et al., 2018 [17] & Paraffin & $\begin{array}{l}\text { Endometrial cancers }(n=156) \text { : } \\
87 \text { FIGO I, } 35 \text { FIGO II, } 23 \text { FIGO III, } 11 \text { FIGO IV }\end{array}$ & $\begin{array}{c}\text { Increased expression of miR-183-5p is associated with } \\
\text { improved prognosis of OS }\end{array}$ \\
\hline Deng et al., 2017 [18] & $-80^{\circ} \mathrm{C}$ & Endometrioid endometrial cancers $(n=90)$ & $\begin{array}{l}\text { A decrease in miR-202 expression is associated with a } \\
\text { significant decrease in OS }(p<0.05)\end{array}$ \\
\hline Tsukamoto et al., 2014 [13] & - & $\begin{array}{l}\text { Endometrioid endometrial cancers }(n=28) \text { : } \\
7 \text { FIGO IA Grade } 1,21 \text { other grades } \\
\qquad 4 \mathrm{~N}+, 21 \mathrm{~N}-\end{array}$ & $\begin{array}{l}\text { The expression levels of miR-135b, }-205,-21,-30 a-3 p,-499 \text {, } \\
-10 b,-30 a-5 p \text {, and }-195 \text { are not correlated with RFS }\end{array}$ \\
\hline Bao et al., 2013 [19] & - & $\begin{array}{l}\text { Endometrioid endometrial cancers from Cancer Genome Atlas } \\
\text { database }(n=279)\end{array}$ & $\begin{array}{l}\text { Increased expression of miR-204-5p is associated with a } \\
\text { nonsignificant improvement in OS (OR }=1.32, p=0.12)\end{array}$ \\
\hline Dong et al., 2013 [20] & Paraffin & $\begin{array}{l}\text { Endometrial cancers followed for } 15 \text { years }(n=32) \text { : } \\
15 \text { endometrioid, } 8 \text { serous, } 5 \text { clear cell, } 4 \text { others, } \\
\text {-18 FIGO I, } 1 \text { FIGO II, } 5 \text { FIGO III, } 8 \text { FIGO IV }\end{array}$ & $\begin{array}{l}\text { Increased expression of miR-130b is associated with better OS } \\
\qquad(p=0.05)\end{array}$ \\
\hline Zhang et al., 2013 [21] & Paraffin & $\begin{array}{c}\text { Endometrial cancers }(n=107) \text { : } \\
85 \text { endometrioid, } 22 \text { others } \\
30 \text { Grade 1, } 39 \text { Grade 2, } 16 \text { Grade } 3 \\
18 \text { LVSI+, } 87 \text { LVSI- } \\
\text { 74 FIGO I, } 17 \text { FIGO II, } 13 \text { FIGO III, } 1 \text { FIGO IV } \\
6 \mathrm{~N}+, 42 \text { N- }\end{array}$ & $\begin{array}{l}\text { The decrease in expression of miR-145 and miR-143 is } \\
\text { associated with a nonsignificant decrease in OS }(p>0.05)\end{array}$ \\
\hline Torres et al., 2013 [14] & $\begin{array}{l}\text { Paraffin } \\
-80^{\circ} \mathrm{C}\end{array}$ & $\begin{array}{l}\text { Endometrioid endometrial cancers }(n=77) \text { : } \\
\qquad 29 \text { Grade } 1,30 \text { Grade } 2,18 \text { Grade } 3 \\
\qquad 15 \mathrm{~N}+, 29 \mathrm{~N}-\end{array}$ & $\begin{array}{l}\text { The expression levels of miR-1228/miR-200c/miR-429 and } \\
\text { miR-1228/miR-429 are respectively associated with OS } \\
\text { (HR: } 2.978,95 \% \text { CI: } 1.580-5.614, p<0.001 \text { ) and RFS } \\
\text { (HR: } 4.149,95 \% \text { CI: } 2.193-7.852, p<0.001 \text { ) }\end{array}$ \\
\hline Zhai et al., 2013 [22] & Paraffin & $\begin{array}{l}\text { Endometrial cancers followed for } 15 \text { years }(n=32) \text { : } \\
15 \text { endometrioid, } 8 \text { serous, } 5 \text { clear cell, } 4 \text { others } \\
17 \text { FIGO I, } 1 \text { FIGO II, } 5 \text { FIGO III, } 9 \text { FIGO IV }\end{array}$ & $\begin{array}{l}\text { Increased expression of miR-194 is associated with better OS } \\
\qquad(p=0.007)\end{array}$ \\
\hline
\end{tabular}


Table 2. Cont.

\begin{tabular}{|c|c|c|c|}
\hline Reference & $\begin{array}{l}\text { Sample } \\
\text { Type }\end{array}$ & Sample Case & Conclusion \\
\hline Karaayvaz et al., 2012 [23] & Paraffin & $\begin{array}{c}\text { Endometrial cancers }(n=48) \text { : } \\
24 \text { endometrioid, } 13 \text { serous, } 5 \text { clear cell, } 6 \text { others } \\
26 \text { FIGO I, } 4 \text { FIGO II, } 6 \text { FIGO III, } 12 \text { FIGO IV }\end{array}$ & $\begin{array}{l}\text { Increased expression of miR-205 is associated with poorer OS } \\
\qquad(p=0.03) \\
\text { Expression of miR-200c is not correlated with OS }(p=0.58)\end{array}$ \\
\hline Torres et al., 2012 [24] & $\begin{array}{l}\text { Paraffin } \\
-80^{\circ} \mathrm{C}\end{array}$ & $\begin{array}{l}\text { Endometrioid endometrial cancers }(n=77) \text { : } \\
29 \text { Grade 1, } 30 \text { Grade 2, } 18 \text { Grade } 3 \\
50 \text { FIGO I, } 5 \text { FIGO II, } 15 \text { FIGO III, } 2 \text { FIGO IV } \\
\qquad 29 \mathrm{~N}+, 15 \mathrm{~N}-\end{array}$ & $\begin{array}{l}\text { Increased expression of miR-100 is associated with better OS } \\
\qquad(p=0.02)\end{array}$ \\
\hline Cohn et al., 2010 [25] & Paraffin & $\begin{array}{l}\text { Endometrial cancers }(n=141): \\
128 \text { endometrioid: } 121 \text { FIGO I, 3 FIGO III, } 4 \text { FIGO IV } \\
13 \text { serous: } 7 \text { FIGO III, } 6 \text { FIGO IV }\end{array}$ & $\begin{array}{l}\text { Increased expression of miR-199a-5p is associated with better } \\
\text { OS }(p=0.007) \text { and better RFS }(p=0.048)\end{array}$ \\
\hline Hiroki et al., 2010 [26] & $-80^{\circ} \mathrm{C}$ & $\begin{array}{l}\text { Serous adenocarcinoma }(n=21) \text { : } \\
8 \text { FIGO I, } 2 \text { FIGO II, } 3 \text { FIGO III, } 8 \text { FIGO IV } \\
\text { 5 LVSI+, } 16 \text { LVSI- }\end{array}$ & $\begin{array}{c}\text { The subexpressions of miR-152, }-29 \mathrm{~b} \text { and }-455-5 \mathrm{p} \text { are } \\
\text { associated with poorer OS and RFS }(p<0.05) . \\
\text { Subexpressions of miR-101, }-10 \mathrm{~b}^{*} \text {, and }-139-5 \mathrm{p} \text { are associated } \\
\text { with poorer OS }(p<0.05)\end{array}$ \\
\hline Huang et al., 2009 [27] & - & Endometrial cancers $(n=117)$ & $\begin{array}{l}\text { Methylation of the miR-129-2 gene is associated with poorer } \\
\qquad \text { OS }(p=0.039)\end{array}$ \\
\hline
\end{tabular}

FIGO: International Federation of Gynecology and Obstetrics, LVSI: lympho-vascular space involvement, N: ganglionic status, OS: overall survival, RFS: recurrence-free survival, HR:

Hazard Ratio. 


\subsection{Relationship between Specific miRs in the Plasma/Serum and the Presence of Endometrial Cancer}

Six studies compared the expression of circulating miRs (six with plasma and one with serum) in patients with EC compared to healthy patients [11,13,14,24,56,57]. The 19 miRs miR-15b, -27a, -92a, $-99 a,-100,-135 b,-141,-143,-186,-199 b,-200 a,-203,-204,-205,-222,-223,-449 a,-1228$, and miR-1290 showed increased expression in EC patients. The 10 miRs miR-9, -21, -30a-3p, -204, -301b, -1179, $-3145-5 p,-4502,-4638-3 p$, and -4665-5p showed decreased expression in EC patients.

A summary of these data is indicated in Supplementary Table S3.

\section{Discussion}

The findings presented here suggest that miR analysis merits a role in the management of patients with endometrial cancer, particularly when associated with prognostic factors such as lymph node status, LVSI, and recurrence-free survival; it can thereby complement the classical anatomo-pathological approach, even if there has been no integration of the miRs into either the anatomical classification or the molecular classification until now [2]. Various studies have focused on miRNAs' implication in endometrial cancer mechanisms [58] with no fully established conclusions. Yet, based on new knowledge of miRNAs associated with different prognoses, new pathogenetic classifications for EC may be proposed including miRNAs as one element among others (i.e., anatomic prognostic features, molecular classification) in order to give better targeting for future treatment. The miRs most frequently implicated in endometrial cancer are miR-182, miR-183, miR-200a, miR-200b, and miR-205, which are overexpressed in tumor tissues, and miR-152, which is underexpressed. However, the identification of these miRs was obtained from a variety of different studies focusing on different aspects.

The data presented here are consistent with studies of the role of miRs in other cancer types. Overexpression of miR-182 was associated with a poorer prognosis in terms of overall survival (Hazard Ratio $(\mathrm{HR})=2.50,95 \%$ CI: $1.86-3.36$ ) and recurrence-free survival (HR $=2.52,95 \%$ CI: $1.67-3.79)$ in a meta-analysis that collected data from patients with different tumor types [58]. Likewise, overexpression of miR-183 seems to be associated with poor prognosis in terms of overall survival ( $\mathrm{HR}=2.642$, 95\% CI: 2.152-3.245) and with tumor progression ( $\mathrm{HR}=2.403,95 \% \mathrm{CI}: 1.267-4.559)$ according to a meta-analysis by Zhang et al. [59].

Mechanistic studies have revealed a role for many miRs in carcinogenic pathways. This is particularly the case for miR 200a, 200b [60], and 205a [61], which are involved in the PI3K/Akt/mTOR signaling pathway, most likely through downregulation of the Phosphatase and TENsin homolog (PTEN) tumor suppressor. However, it has been shown that there is a high prevalence of PTEN gene mutation (56-57\%) [62,63], PI3K gene mutation (36-39\%) [62,63], or even the associated mutation of these two genes (25\%) [63]. The loss of PTEN induces a lack of control of A phosphorylation, while the mutation of the gene coding for the p85 subunit of PI3K is involved in the overactivation of Akt, both resulting in cell proliferation and resistance to apoptosis [64]. This signaling pathway is also a therapeutic target under study; the use of a PI3K/mTOR inhibitor and the use of temsirolimus as an mTOR inhibitor appears to be effective on cells presenting these mutations [65]. Otherwise, overexpression of miR-182 inhibits the expression of cullin-5 (CUL5), the overexpression of which leads to a reduction in cell proliferation and the CUL5-RING E3 (i.e., Really Interesting New Gene E3) ligase complex [66]. miR-183 has a role in the induction of the epithelio-mesenchymal transition, in apoptosis inhibition, and in the promotion of cell proliferation by downregulating cytoplasmic polyadenylation element-binding protein 1 (CPEB1) [67]. Finally, the subexpression of miR-152 induces a decrease in the expression of PTEN, a tumor suppressor gene having a fundamental role in the inhibition of cell proliferation, particularly in EC [68].

One of the crucial difficulties in the management of patients with EC is to establish a guideline for when to perform lymphadenectomy associated with hysterectomy in the initial surgical management. To date, no imaging technique $[69,70]$ or preoperative histological analysis [70-72] makes it possible to accurately define the risk of ganglionic invasion. A determination of miR expression in the primitive tumor tissue might provide some guidelines. Unfortunately, most studies that have examined the 
correlation between miR expression and lymph node status in EC [13,14,19,21,24-26,41,48,53-55] have included several histological types and grades, with data from secondary analyses. However, expression levels of miR-34 and miR-184 may be useful for adapting patient care, since Canlorbe et al. [53] showed that a decrease in miR-34c-5p and miR-184 was associated with positive lymph node status in patients with otherwise good prognosis.

Interestingly, decreased expression of miR-34 was also identified as a negative prognostic factor for a different type of EC, since decreased expression of miR-34 in serous-type endometrial cancer is strongly associated with LVSI [26]. This data strengthens the knowledge about the miR-34 family (miR-34a, b, and c) which seems to act as a tumor suppressor miR in many cancers [73]. Interestingly, miR-34 is a direct target of tumor protein 53 (TP53)/p53, a tumor suppressor gene resulting in cell cycle arrest and apoptosis when activated under cellular stress [74]. Many studies have previously demonstrated a dysregulation of miR-34 in several cancers, including melanoma, hepatocellular, mesothelial, colic, nasopharyngeal, leukemia [75], prostate cancer [76], neuroblastoma [77], glioblastoma [78], and breast cancer [79]. However, to date, few studies have addressed its role in EC, except for a functional study by Li et al. [80] demonstrating that miR-34c acts as a tumor suppressor miR in human endometrial cancer $1 \mathrm{~b}(\mathrm{HEC}-1 \mathrm{~b})$ with the E2F transcription factor 3 (E2F3) being one of the targets. It has also been reported that decreased expression of miR-184 is associated with recurrence in endometrial cancer [81].

An attractive feature of miRs is that they are relatively stable in serum, suggesting that liquid biopsies might be useful for miR analysis in different clinical situations. Several studies have used miR analysis to identify individuals with EC. The expression of miR-27a in association with cancer antigen 125 (CA-125) may be able to distinguish between healthy subjects and patients with endometrioid adenocarcinoma with an area under the curve of 0.894 (95\% CI, 0.807-0.980, a sensitivity of 0.78, and a specificity of 0.97 ) [82]. Another study concluded that serum expression levels of four miRs (miR-222, $-223,-186$, and -204) allow us to distinguish between patients with endometrioid adenocarcinoma and healthy subjects with an area under the curve of 0.927 (95\% CI 0.85-1.00, a sensitivity of 91.7\%, and a specificity of $87.5 \%$ ) [11]. According to the same study, the diagnostic performance of these four miRs was much higher than that of the classical serum marker CA-125, which has an area under the curve of 0.673 (95\% CI 0.525-0.821) [11]. Although these findings are encouraging, there are limits to the use of miRs. Indeed, the reproducibility of their detection and quantification is relatively low. This is due to several factors. The accuracy, reproducibility, sensitivity, and specificity of the main PCR kits were compared by Mestdagh et al. [83], and they present a great disparity in performance. There is also currently no consensus regarding the use of housekeeping genes as endogenous internal control when assessing miRNA expression. The housekeeping genes are conventionally selected from a panel of 12 non-coding RNAs (RNU48, RNU44, U75, RNU6B, U6, U54, RNU38B, U18, U49, miR-26b, miR-92a, and miR-16) described as stable in tissues or at least used in EC studies [49,84]. Their expression nevertheless shows considerable variability according to some authors [13] and could lead to errors of interpretation and non-reproducibility of the results according to the histological types concerned.

A new technique for the detection and quantification of miRs using isothermally amplified time-gated Förster resonance energy transfer (TG-FRET) that has shown interest in breast and ovarian cancer could overcome these drawbacks in EC [85].

Regarding the analysis of miR expression in plasma and serum, we found that among the $33 \mathrm{miRs}$ identified, only miRNA-223 had been described three times before [11,56,82], while miRs -186 and -222 had been described twice before $[11,56]$. The lack of reproducibility may be explained by two main reasons: the heterogeneity of the patient samples and the diversity of the detection techniques. The use of liquid-based cytology could be a non-invasive alternative technique to the collection of plasma samples to highlight the dysregulation of some miRs as shown by Kottaridi et al. [86]. The different studies compared subjects who were thought to be in good health with EC patients. However, the latest data in the literature clearly demonstrated that within the same histological type (here, endometrioid), there can be several molecular subtypes which display diverse mutations of genes such as PTEN, 
KRAS (i.e., Kirsten rat sarcoma viral oncogene homolog), $\beta$-catenin, or microsatellite instability [2], which would lead to altered miR synthesis.

Furthermore, there is no consensus on the techniques for measuring and comparing expression levels of miRs in plasma or serum. Panels of highly expressed miRs in plasma, such as miR-93, miR-26b, miR-192, miR-103a, miR-142-3p, miR-92a, miR-638, miR-16, and miR-451, may serve as "household" miRs [87-90] that can be used for standardization of other miRs. For example, in one study the crude results were normalized with five miRs-miR-93, miR-26b, miR-192, miR-103a, and miR-142-3p [24]. The same team also proposed to normalize the expression of the miRs of interest with that of Caenorhabditis elegans oligonucleotides that had been added to the reaction mixture, including cel-miR-39, cel-miR-54, and cel-miR-238 [14,24]. Wang et al. also performed the normalization of studied miRs with cel-miR-39 [60]. Two other studies determined the absolute concentrations of miRs using calibration curves created with known concentrations of synthetic miRs $\left(10^{-6} \mathrm{fM} / 1\right)[11,13]$.

Recently, several reviews have focused on the potential therapeutic use of targeting miRs in cancer [7,91], including EC [55]. These reviews underlined that global suppression of miRs is not compatible with survival, since deletion of the Dicer complex, which is needed for a common step in miR biosynthesis, is lethal [92]. Any therapeutic strategy based on their use can therefore be conceived only in a targeted way directed toward one or a few miRs.

Upregulation of a suppressor miR would require an agonist-type strategy with reintroduction of the miR of interest or a functionally similar analogue. Conversely, reducing the level of an onco-miR would need an antagonistic strategy by oligonucleotides complementary to the miR in question, hence the name "antagomir" [93] or "AMO" (anti-miR oligonucleotide) [94]. Several reviews have addressed this problem with very similar conclusions [95-98]. Whatever the strategy used, it faces the same two major obstacles: the difficulty of getting these highly negatively charged molecules to penetrate the cells and their stability with respect to the nucleases present in the blood and in the cells. These are the same difficulties encountered by the use of therapeutic siRNAs (interfering RNAs). The panoply of possible chemical modifications used to overcome these problems is detailed in a review by Saumet et al. [99]. Finally, the possibility of introducing these oligonucleotide sequences by gene therapy vectors is also being actively explored.

\section{Conclusions}

miR analysis of endometrial tumor tissue complements the classical anatomo-pathological approach adding prognostic and therapeutic value. In particular, certain miR expression profiles are associated with important prognostic factors such as lymph node status and the presence of emboli. miR analysis may be simplified for routine clinical use, provided that data collection and analysis techniques are standardized.

Supplementary Materials: The following are available online at http://www.mdpi.com/2072-6694/11/6/832/s1, Table S1: miRs involved in endometrial cancer, Table S2: Expression profile of miRs within neoplastic endometrial tissue according to the associated ganglionic status, Table S3: Relationship between plasma/serum miRs and endometrial cancer.

Author Contributions: Conceptualization of the study: R.D. and G.C.; methodology: M.B. and C.G.; validation: A.K.L.; data curation and bibliography: R.D., T.D.F., M.B. and G.C.; writing-original draft preparation, R.D.; writing-review and editing: R.D. and G.C.; critical revision of the manuscript of important intellectual content: A.K.L., M.S., H.A., S.B., E.D., C.M., C.U.; supervision: G.C.

Funding: This research received no external funding.

Conflicts of Interest: The authors declare no conflict of interest. 


\section{References}

1. World Health Organization. Datas from International Agency for Research on Cancer. Available online: http://gco.iarc.fr/today/online-analysis-table?v=2018\&mode=cancer\&mode_population=continents\& population $=900 \&$ populations $=900 \& \mathrm{key}=$ asr \&sex $=0 \&$ cancer $=39 \&$ type $=0 \&$ statistic $=5 \&$ prevalence $=0 \&$ population_group=0\&ages_group $\% 5 \mathrm{~B} \% 5 \mathrm{D}=0$ \&ages_group $\% 5 \mathrm{~B} \% 5 \mathrm{D}=17 \& \mathrm{nb}$ _items $=5 \&$ group_cancer $=1$ \& include_nmsc=1\&include_nmsc_other=1 (accessed on 31 January 2019).

2. Morice, P.; Leary, A.; Creutzberg, C.; Abu-Rustum, N.; Darai, E. Endometrial cancer. Lancet 2016, 387, 1094-1108. [CrossRef]

3. Soslow, R.A.; Tornos, C.; Park, K.J.; Malpica, A.; Matias-Guiu, X.; Oliva, E.; Parkash, V.; Carlson, J.; McCluggage, W.G.; Gilks, C.B. Endometrial carcinoma diagnosis: Use of figo grading and genomic subcategories in clinical practice: Recommendations of the international society of gynecological pathologists. Int. J. Gynecol. Pathol. 2019, 38 (Suppl. 1), S64-S74. [CrossRef] [PubMed]

4. Cancer Genome Atlas Research Network; Kandoth, C.; Schultz, N. Integrated genomic characterization of endometrial carcinoma. Nature 2013, 497, 67-73. [CrossRef] [PubMed]

5. Felli, N.; Fontana, L.; Pelosi, E.; Botta, R.; Bonci, D.; Facchiano, F.; Liuzzi, F.; Lulli, V.; Morsilli, O.; Santoro, S.; et al. MicroRNAs 221 and 222 inhibit normal erythropoiesis and erythroleukemic cell growth via kit receptor down-modulation. Proc. Natl. Acad. Sci. USA 2005, 102, 18081-18086. [CrossRef] [PubMed]

6. Iorio, M.V.; Ferracin, M.; Liu, C.-G.; Veronese, A.; Spizzo, R.; Sabbioni, S.; Magri, E.; Pedriali, M.; Fabbri, M.; Campiglio, M.; et al. MicroRNA gene expression deregulation in human breast cancer. Cancer Res. 2005, 65, 7065-7070. [CrossRef] [PubMed]

7. Jeanteur, P. miRNAs and cancer. Bull. Cancer 2010, 97, 1231-1239. [CrossRef] [PubMed]

8. Guo, H.; Ingolia, N.T.; Weissman, J.S.; Bartel, D.P. Mammalian microRNAs predominantly act to decrease target mRNA levels. Nature 2010, 466, 835-840. [CrossRef]

9. Yang, Q.; Lu, J.; Wang, S.; Li, H.; Ge, Q.; Lu, Z. Application of next-generation sequencing technology to profile the circulating microRNAs in the serum of preeclampsia versus normal pregnant women. Clin. Chim. Acta 2011, 412, 2167-2173. [CrossRef]

10. Lee, T.S.; Jeon, H.W.; Kim, Y.B.; Kim, Y.A.; Kim, M.A.; Kang, S.B. Aberrant MicroRNA expression in endometrial carcinoma using formalin-fixed paraffin-embedded (FFPE) tissues. PLoS ONE 2013, 8, e81421. [CrossRef]

11. Jia, W.; Wu, Y.; Zhang, Q.; Gao, G.; Zhang, C.; Xiang, Y. Identification of four serum microRNAs from a genome-wide serum microRNA expression profile as potential non-invasive biomarkers for endometrioid endometrial cancer. Oncol. Lett. 2013, 6, 261-267. [CrossRef]

12. Liu, T.; Gao, H.; Yang, M.; Zhao, T.; Liu, Y.; Lou, G. Correlation of TNFAIP8 overexpression with the proliferation, metastasis, and disease-free survival in endometrial cancer. Tumor Boil. 2014, 35, 5805-5814. [CrossRef] [PubMed]

13. Tsukamoto, O.; Miura, K.; Mishima, H.; Abe, S.; Kaneuchi, M.; Higashijima, A.; Miura, S.; Kinoshita, A.; Yoshiura, K.-I.; Masuzaki, H. Identification of endometrioid endometrial carcinoma-associated microRNAs in tissue and plasma. Gynecol. Oncol. 2014, 132, 715-721. [CrossRef] [PubMed]

14. Torres, A.; Torres, K.; Pesci, A.; Ceccaroni, M.; Paszkowski, T.; Cassandrini, P.; Zamboni, G.; Maciejewski, R. Diagnostic and prognostic significance of miRNA signatures in tissues and plasma of endometrioid endometrial carcinoma patients. Int. J. Cancer 2013, 132, 1633-1645. [CrossRef] [PubMed]

15. Canlorbe, G.; Castela, M.; Bendifallah, S.; Wang, Z.; Lefevre, M.; Chabbert-Buffet, N.; Aractingi, S.; Darai, E.; Méhats, C.; Ballester, M. Micro-RNA signature of lymphovascular space involvement in type 1 endometrial cancer. Histol. Histopathol. 2017, 32, 941-950. [CrossRef]

16. Wang, Y.; Xu, M.; Yang, Q. A six-microRNA signature predicts survival of patients with uterine corpus endometrial carcinoma. Curr. Probl. Cancer 2019, 43, 167-176. [CrossRef] [PubMed]

17. Yan, H.; Sun, B.; Zhang, Y.; Li, Y.; Huang, C.; Feng, F.; Li, C. Upregulation of miR-183-5p is responsible for the promotion of apoptosis and inhibition of the epithelial-mesenchymal transition, proliferation, invasion and migration of human endometrial cancer cells by downregulating Ezrin. Int. J. Mol. Med. 2018, 42, 2469-2480. [CrossRef]

18. Deng, X.; Hou, C.; Liang, Z.; Wang, H.; Zhu, L.; Xu, H. miR-202 suppresses cell proliferation by targeting FOXR2 in endometrial adenocarcinoma. Dis. Mark. 2017, 2017, 2827435. [CrossRef] 
19. Bao, W.; Wang, H.-H.; Tian, F.-J.; He, X.-Y.; Qiu, M.-T.; Wang, J.-Y.; Zhang, H.-J.; Wang, L.-H.; Wan, X.-P. A TrkB-STAT3-miR-204-5p regulatory circuitry controls proliferation and invasion of endometrial carcinoma cells. Mol. Cancer 2013, 12, 155. [CrossRef]

20. Dong, P.; Karaayvaz, M.; Jia, N.; Kaneuchi, M.; Hamada, J.; Watari, H.; Sudo, S.; Ju, J.; Sakuragi, N. Mutant p53 gain-of-function induces epithelial-mesenchymal transition through modulation of the miR-130b-ZEB1 axis. Oncogene 2013, 32, 3286-3295. [CrossRef]

21. Zhang, X.; Dong, Y.; Ti, H.; Zhao, J.; Wang, Y.; Li, T.; Zhang, B. Down-regulation of miR-145 and miR-143 might be associated with DNA methyltransferase 3B overexpression and worse prognosis in endometrioid carcinomas. Hum. Pathol. 2013, 44, 2571-2580. [CrossRef]

22. Zhai, H.; Karaayvaz, M.; Dong, P.; Sakuragi, N.; Ju, J. Prognostic significance of miR-194 in endometrial cancer. Biomark. Res. 2013, 1, 12. [CrossRef] [PubMed]

23. Karaayvaz, M.; Zhang, C.; Liang, S.; Shroyer, K.R.; Ju, J. Prognostic significance of miR-205 in endometrial cancer. PLoS ONE 2012, 7, e35158. [CrossRef] [PubMed]

24. Torres, A.; Torres, K.; Pesci, A.; Ceccaroni, M.; Paszkowski, T.; Cassandrini, P.; Zamboni, G.; Maciejewski, R. Deregulation of miR-100, miR-99a and miR-199b in tissues and plasma coexists with increased expression of mTOR kinase in endometrioid endometrial carcinoma. BMC Cancer 2012, 12, 369. [CrossRef] [PubMed]

25. Cohn, D.E.; Fabbri, M.; Valeri, N.; Alder, H.; Ivanov, I.; Liu, C.-G.; Croce, C.M.; Resnick, K.E. Comprehensive miRNA profiling of surgically staged endometrial cancer. Am. J. Obstet. Gynecol. 2010, 202, 656.e1-656.e8. [CrossRef] [PubMed]

26. Hiroki, E.; Akahira, J.-I.; Suzuki, F.; Nagase, S.; Ito, K.; Suzuki, T.; Sasano, H.; Yaegashi, N. Changes in microRNA expression levels correlate with clinicopathological features and prognoses in endometrial serous adenocarcinomas. Cancer Sci. 2010, 101, 241-249. [CrossRef]

27. Huang, Y.-W.; Liu, J.C.; Deatherage, D.E.; Luo, J.; Mutch, D.G.; Goodfellow, P.J.; Miller, D.S.; Huang, T.H.-M. Epigenetic repression of microRNA-129-2 leads to overexpression of SOX4 oncogene in endometrial cancer. Cancer Res. 2009, 69, 9038-9046. [CrossRef]

28. Liu, Y.; Li, H.; Zhao, C.; Jia, H. MicroRNA-101 inhibits angiogenesis via COX-2 in endometrial carcinoma. Mol. Cell. Biochem. 2018, 448, 61-69. [CrossRef]

29. Liu, J.; Li, C.; Jiang, Y.; Wan, Y.; Zhou, S.; Cheng, W. Tumor-suppressor role of miR-139-5p in endometrial cancer. Cancer Cell Int. 2018, 18, 51. [CrossRef]

30. Ma, J.; Li, D.; Kong, F.-F.; Yang, D.; Yang, H.; Ma, X.-X. miR-302a-5p/367-3p-HMGA2 axis regulates malignant processes during endometrial cancer development. J. Exp. Clin. Cancer Res. 2018, 37, 19. [CrossRef]

31. Huang, C.; Hu, G. Shikonin suppresses proliferation and induces apoptosis in endometrioid endometrial cancer cells via modulating miR-106b/PTEN/AKT/mTOR signaling pathway. Biosci. Rep. 2018, 38, 3055-3060. [CrossRef]

32. Ushakov, D.S.; Dorozhkova, A.S.; Babayants, E.V.; Ovchinnikov, V.Y.; Kushlinskii, D.N.; Adamyan, L.V.; Gulyaeva, L.F.; Kushlinskii, N.E. Expression of microRNA Potentially Regulated by AhR and CAR in Malignant Tumors of the Endometrium. Bull. Exp. Boil. Med. 2018, 165, 688-691. [CrossRef] [PubMed]

33. Xie, P.; Cao, H.; Li, Y.; Wang, J.; Cui, Z. Knockdown of lncRNA CCAT2 inhibits endometrial cancer cells growth and metastasis via sponging miR-216b. Cancer Biomark. 2017, 21, 123-133. [CrossRef] [PubMed]

34. Zhang, S.; Wang, M.; Li, Q.; Zhu, P. MiR-101 reduces cell proliferation and invasion and enhances apoptosis in endometrial cancer via regulating PI3K/Akt/mTOR. Cancer Biomark. 2017, 21, 179-186. [CrossRef] [PubMed]

35. Fan, Y.; Xu, W.; Meng, Y.; Fang, D.; Wang, J.; Chen, H. Exploration of miR-1202 and miR-196a in human endometrial cancer based on high throughout gene screening analysis. Oncol. Rep. 2017, 37, 3493-3501.

36. He, Z.; Xu, H.; Meng, Y.; Kuang, Y. miR-944 acts as a prognostic marker and promotes the tumor progression in endometrial cancer. Biomed. Pharmacother. 2017, 88, 902-910. [CrossRef] [PubMed]

37. Wang, Z.; Wang, W.; Huang, K.; Wang, Y.; Li, J.; Yang, X. MicroRNA-34a inhibits cells proliferation and invasion by downregulating Notch1 in endometrial cancer. Oncotarget 2017, 8, 111258-111270. [CrossRef]

38. Cai, Y.; He, T.; Liang, L.; Zhang, X.; Yuan, H. Upregulation of microRNA-337 promotes the proliferation of endometrial carcinoma cells via targeting PTEN. Mol. Med. Rep. 2016, 13, 4827-4834. [CrossRef] [PubMed]

39. Zhao, X.; Zhu, D.; Lu, C.; Yan, D.; Li, L.; Chen, Z. MicroRNA-126 inhibits the migration and invasion of endometrial cancer cells by targeting insulin receptor substrate 1. Oncol. Lett. 2016, 11, 1207-1212. [CrossRef] 
40. Yoneyama, K.; Ishibashi, O.; Kawase, R.; Kurose, K.; Takeshita, T. miR-200a, miR-200b and miR-429 are onco-miRs that target the PTEN gene in endometrioid endometrial carcinoma. Anticancer. Res. 2015, 35, 1401-1410.

41. Zeng, S.; Zhou, Z.-W.; He, Z.-X.; Zhou, S.-F.; He, S.-M.; He, Z. Hsa-microRNA-181a is a regulator of a number of cancer genes and a biomarker for endometrial carcinoma in patients: A bioinformatic and clinical study and the therapeutic implication. Drug Des. Dev. Ther. 2015, 9, 1103-1175.

42. Kong, X.; Xu, X.; Yan, Y.; Guo, F.; Li, J.; Hu, Y.; Zhou, H.; Xun, Q. Estrogen regulates the tumour suppressor MiRNA-30c and its target gene, MTA-1, in endometrial cancer. PLoS ONE 2014, 9, e90810. [CrossRef] [PubMed]

43. Jurcevic, S.; Klinga-Levan, K.; Olsson, B.; Ejeskär, K. Verification of microRNA expression in human endometrial adenocarcinoma. BMC Cancer 2016, 16, 227. [CrossRef] [PubMed]

44. Xu, Y.-Y.; Wu, H.-J.; Ma, H.-D.; Xu, L.-P.; Huo, Y.; Yin, L.-R. MicroRNA-503 suppresses proliferation and cell-cycle progression of endometrioid endometrial cancer by negatively regulating cyclin D1. FEBS J. 2013, 280, 3768-3779. [CrossRef] [PubMed]

45. Lee, H.; Choi, H.J.; Kang, C.S.; Lee, H.J.; Lee, W.S.; Park, C.S. Expression of miRNAs and PTEN in endometrial specimens ranging from histologically normal to hyperplasia and endometrial adenocarcinoma. Mod. Pathol. 2012, 25, 1508-1515. [CrossRef] [PubMed]

46. Snowdon, J.; Zhang, X.; Childs, T.; Tron, V.A.; Feilotter, H. The MicroRNA-200 family is upregulated in endometrial carcinoma. PLoS ONE 2011, 6, e22828. [CrossRef] [PubMed]

47. Ratner, E.S.; Tuck, D.; Richter, C.; Nallur, S.; Patel, R.M.; Schultz, V.; Hui, P.; Schwartz, P.E.; Rutherford, T.J.; Weidhaas, J.B. MicroRNA signatures differentiate uterine cancer tumor subtypes. Gynecol. Oncol. 2010, 118, 251-257. [CrossRef] [PubMed]

48. Chung, T.K.; Cheung, T.-H.; Huen, N.-Y.; Wong, K.W.; Lo, K.W.; Yim, S.-F.; Siu, N.S.; Wong, Y.-M.; Tsang, P.-T.; Pang, M.-W.; et al. Dysregulated microRNAs and their predicted targets associated with endometrioid endometrial adenocarcinoma in Hong Kong women. Int. J. Cancer 2009, 124, 1358-1365. [CrossRef]

49. Wu, W.; Lin, Z.; Zhuang, Z.; Liang, X. Expression profile of mammalian microRNAs in endometrioid adenocarcinoma. Eur. J. Cancer Prev. 2009, 18, 50-55. [CrossRef]

50. Boren, T.; Xiong, Y.; Hakam, A.; Wenham, R.; Apte, S.; Wei, Z.; Kamath, S.; Chen, D.-T.; Dressman, H.; Lancaster, J.M. MicroRNAs and their target messenger RNAs associated with endometrial carcinogenesis. Gynecol. Oncol. 2008, 110, 206-215. [CrossRef]

51. Fang, Q.; Sang, L.; Du, S. Long noncoding RNA LINC00261 regulates endometrial carcinoma progression by modulating miRNA/FOXO1 expression. Cell Biochem. Funct. 2018, 36, 323-330. [CrossRef]

52. Xiong, H.; Li, Q.; Liu, S.; Wang, F.; Xiong, Z.; Chen, J.; Chen, H.; Yang, Y.; Tan, X.; Luo, Q.; et al. Integrated microRNA and mRNA transcriptome sequencing reveals the potential roles of miRNAs in stage I endometrioid endometrial carcinoma. PLoS ONE 2014, 9, e110163. [CrossRef] [PubMed]

53. Canlorbe, G.; Wang, Z.; Laas, E.; Bendifallah, S.; Castela, M.; Lefèvre, M.; Chabbert-Buffet, N.; Daraï, E.; Aractingi, S.; Méhats, C.; et al. Identification of microRNA expression profile related to lymph node status in women with early-stage grade 1-2 endometrial cancer. Mod. Pathol. 2016, 29, 391-401. [CrossRef] [PubMed]

54. Li, Y.; Zhang, Z.; Zhang, X.; Lin, Y.; Luo, T.; Xiao, Z.; Zhou, Q. A dual PI3K/AKT/mTOR signaling inhibitor miR-99a suppresses endometrial carcinoma. Am. J. Transl. Res. 2016, 8, 719-731. [PubMed]

55. Liu, B.; Che, Q.; Qiu, H.; Bao, W.; Chen, X.; Lü, W.; Li, B.; Wan, X. Elevated MiR-222-3p Promotes Proliferation and Invasion of Endometrial Carcinoma via Targeting ER $\alpha$. PLoS ONE 2014, 9, e87563. [CrossRef] [PubMed]

56. Montagnana, M.; Benati, M.; Danese, E.; Giudici, S.; Perfranceschi, M.; Ruzzenenete, O.; Salvagno, G.L.; Bassi, A.; Gelati, M.; Paviati, E.; et al. Aberrant MicroRNA expression in patients with endometrial cancer. Int. J. Gynecol. Cancer 2017, 27, 459-466. [CrossRef]

57. Wang, L.; Chen, Y.-J.; Xu, K.; Xu, H.; Shen, X.-Z.; Tu, R.-Q. Circulating microRNAs as a fingerprint for endometrial endometrioid adenocarcinoma. PLoS ONE 2014, 9, e110767. [CrossRef] [PubMed]

58. Wang, F.; Zhong, S.; Zhang, H.; Zhang, W.; Zhang, H.; Wu, X.; Chen, B. Prognostic value of MicroRNA-182 in cancers: A meta-analysis. Dis. Mark. 2015, 2015, 482146. [CrossRef]

59. Zhang, X.L.; Pan, S.H.; Yan, J.J.; Xu, G. The prognostic value of microRNA-183 in human cancers: A meta-analysis. Medicine 2018, 97, e11213. [CrossRef]

60. Lu, R.-L.; Li, J.-X.; Rong, L.-J.; Wu, Q. MiR-200a and miR-200b target PTEN to regulate the endometrial cancer cell growth in vitro. Asian Pac. J. Trop. Med. 2017, 10, 498-502. 
61. Zhuo, Z.; Yu, H. miR-205 inhibits cell growth by targeting AKT-mTOR signaling in progesterone-resistant endometrial cancer Ishikawa cells. Oncotarget 2017, 8, 28042-28051. [CrossRef]

62. Hayes, M.P.; Wang, H.; Espinal-Witter, R.; Douglas, W.; Solomon, G.J.; Baker, S.J.; Ellenson, L.H. PIK3CA and PTEN mutations in uterine endometrioid carcinoma and complex atypical hyperplasia. Clin. Cancer Res. 2006, 12, 5932-5935. [CrossRef] [PubMed]

63. Oda, K.; Stokoe, D.; Taketani, Y.; McCormick, F. High frequency of coexistent mutations ofPIK3CA and PTENGenes in endometrial carcinoma. Cancer Res. 2005, 65, 10669-10673. [CrossRef] [PubMed]

64. Chen, J.; Zhao, K.-N.; Li, R.; Shao, R.; Chen, C. Activation of PI3K/Akt/mTOR pathway and dual inhibitors of PI3K and mTOR in endometrial cancer. Curr. Med. Chem. 2014, 21, 3070-3080. [CrossRef] [PubMed]

65. Weigelt, B.; Warne, P.H.; Lambros, M.B.; Reis-Filho, J.S.; Downward, J. PI3K pathway dependencies in endometrioid endometrial cancer cell lines. Clin. Cancer Res. 2013, 19, 3533-3544. [CrossRef] [PubMed]

66. Devor, E.J.; Schickling, B.M.; Reyes, H.D.; Warrier, A.; Lindsay, B.; Goodheart, M.J.; Santillan, D.A.; Leslie, K.K. Cullin-5, a ubiquitin ligase scaffold protein, is significantly underexpressed in endometrial adenocarcinomas and is a target of miR-182. Oncol. Rep. 2016, 35, 2461-2465. [CrossRef]

67. Xiong, H.; Chen, R.; Liu, S.; Lin, Q.; Chen, H.; Jiang, Q. MicroRNA-183 induces epithelial-mesenchymal transition and promotes endometrial cancer cell migration and invasion in by targeting CPEB1. J. Cell. Biochem. 2018, 119, 8123-8137. [CrossRef] [PubMed]

68. Djati, M.S.; Rifa'i, M. Role of MicroRNAs in carcinogenesis that potential for biomarker of endometrial cancer. Ann. Med. Surg. 2016, 7, 9-13. [CrossRef]

69. Chi, D.; Barakat, R.; Palayekar, M.; Levine, D.; Sonoda, Y.; Alektiar, K.; Brown, C.; Abu-Rustum, N. The incidence of pelvic lymph node metastasis by FIGO staging for patients with adequately surgically staged endometrial adenocarcinoma of endometrioid histology. Int. J. Gynecol. Cancer 2008, 18, 269-273. [CrossRef]

70. Frumovitz, M.; Singh, D.K.; Meyer, L.; Smith, D.H.; Wertheim, I.; Resnik, E.; Bodurka, D.C. Predictors of final histology in patients with endometrial cancer. Gynecol. Oncol. 2004, 95, 463-468. [CrossRef]

71. Phelippeau, J.; Canlorbe, G.; Bendifallah, S.; Naoura, I.; Lefevre, M.; Ballester, M.; Daraï, E. Preoperative diagnosis of tumor grade and type in endometrial cancer by pipelle sampling and hysteroscopy: Results of a French study. Surg. Oncol. 2016, 25, 370-377. [CrossRef]

72. Eltabbakh, G.H.; Shamonki, J.; Mount, S.L. Surgical stage, final grade, and survival of women with endometrial carcinoma whose preoperative endometrial biopsy shows well-differentiated tumors. Gynecol. Oncol. 2005, 99, 309-312. [CrossRef] [PubMed]

73. Agostini, M.; Knight, R.A. miR-34: From bench to bedside. Oncotarget 2014, 5, 872-881. [CrossRef] [PubMed]

74. Navarro, F.; Lieberman, J. miR-34 and p53: New insights into a complex functional relationship. PLoS ONE 2015, 10. [CrossRef] [PubMed]

75. Li, Y.-Q.; Ren, X.-Y.; He, Q.-M.; Xu, Y.-F.; Tang, X.-R.; Sun, Y.; Zeng, M.-S.; Kang, T.-B.; Liu, N.; Ma, J. MiR-34c suppresses tumor growth and metastasis in nasopharyngeal carcinoma by targeting MET. Cell Death Dis. 2015, 6, e1618. [CrossRef] [PubMed]

76. Hagman, Z.; Haflidadottir, B.S.; Ansari, M.; Persson, M.; Bjartell, A.; Edsjö, A.; Ceder, Y. The tumour suppressor miR-34c targets MET in prostate cancer cells. Br. J. Cancer 2013, 109, 1271-1278. [CrossRef] [PubMed]

77. Welch, C.; Chen, Y.; Stallings, R.L. MicroRNA-34a functions as a potential tumor suppressor by inducing apoptosis in neuroblastoma cells. Oncogene 2007, 26, 5017-5022. [CrossRef] [PubMed]

78. Gao, H.; Zhao, H.; Xiang, W. Expression level of human miR-34a correlates with glioma grade and prognosis. J. Neuro Oncol. 2013, 113, 221-228. [CrossRef]

79. Yu, F.; Jiao, Y.; Zhu, Y.; Wang, Y.; Zhu, J.; Cui, X.; Liu, Y.; He, Y.; Park, E.Y.; Zhang, H.; et al. MicroRNA 34c gene down-regulation via DNA methylation promotes self-renewal and epithelial-mesenchymal transition in breast tumor-initiating cells. J. Biol. Chem. 2012, 287, 465-473. [CrossRef]

80. Li, F.; Chen, H.; Huang, Y.; Zhang, Q.; Xue, J.; Liu, Z.; Zheng, F. miR-34c plays a role of tumor suppressor in HEC-1-B cells by targeting E2F3 protein. Oncol. Rep. 2015, 33, 3069-3074. [CrossRef]

81. De Foucher, T.; Sbeih, M.; Uzan, J.; Bendifallah, S.; Lefevre, M.; Chabbert-Buffet, N.; Aractingi, S.; Uzan, C.; Alsalam, I.A.; Mitri, R.; et al. Identification of micro-RNA expression profile related to recurrence in women with ESMO low-risk endometrial cancer. J. Transl. Med. 2018, 16, 131. [CrossRef] 
82. Iguchi, H.; Kosaka, N.; Ochiya, T. Secretory microRNAs as a versatile communication tool. Commun. Integr. Boil. 2010, 3, 478-481. [CrossRef] [PubMed]

83. Mestdagh, P.; Hartmann, N.; Baeriswyl, L.; Andreasen, D.; Bernard, N.; Chen, C.; Cheo, D.; D'Andrade, P.; DeMayo, M.; Dennis, L.; et al. Evaluation of quantitative miRNA expression platforms in the microRNA quality control (miRQC) study. Nat. Methods 2014, 11, 809-815. [CrossRef] [PubMed]

84. Lee, J.-W.; Park, Y.-A.; Choi, J.-J.; Lee, Y.Y.; Kim, C.-J.; Choi, C.; Kim, T.-J.; Lee, N.W.; Kim, B.-G.; Bae, D.-S. The expression of the miRNA-200 family in endometrial endometrioid carcinoma. Gynecol. Oncol. 2011, 120, 56-62. [CrossRef] [PubMed]

85. Qiu, X.; Xu, J.; Guo, J.; Ammar, A.Y.; Kapetanakis, N.-I.; Duroux-Richard, I.; Unterluggauer, J.J.; Golob-Schwarzl, N.; Regeard, C.; Uzan, C.; et al. Advanced microRNA-based cancer diagnostics using amplified time-gated FRET. Chem. Sci. 2018, 9, 8046-8055. [CrossRef] [PubMed]

86. Kottaridi, C.; Spathis, A.; Margari, N.; Koureas, N.; Terzakis, E.; Chrelias, C.; Pappas, A.; Bilirakis, E.; Pouliakis, A.; Panayiotides, I.J.; et al. Evaluation analysis of miRNAs overexpression in liquid-based cytology endometrial samples. J. Cancer 2017, 8, 2699-2703. [CrossRef] [PubMed]

87. Lawrie, C.H.; Gal, S.; Dunlop, H.M.; Pushkaran, B.; Liggins, A.P.; Pulford, K.; Banham, A.H.; Pezzella, F.; Boultwood, J.; Wainscoat, J.S.; et al. Detection of elevated levels of tumour-associated microRNAs in serum of patients with diffuse large B-cell lymphoma. Br. J. Haematol. 2008, 141, 672-675. [CrossRef] [PubMed]

88. Chen, X.; Bonnefoi, H.; Diebold-Berger, S.; Lyautey, J.; Lederrey, C.; Faltin-Traub, E.; Stroun, M.; Anker, P. Detecting tumor-related alterations in plasma or serum DNA of patients diagnosed with breast cancer. Clin. Cancer Res. 1999, 5, 2297-2303.

89. Resnick, K.E.; Alder, H.; Hagan, J.P.; Richardson, D.L.; Croce, C.M.; Cohn, D.E. The detection of differentially expressed microRNAs from the serum of ovarian cancer patients using a novel real-time PCR platform. Gynecol. Oncol. 2009, 112, 55-59. [CrossRef]

90. Profiling. Profiling of microRNA in Blood, Serum/Plasma. Available online: http://www.exiqon.com/ls/ Documents/Scientific/microRNA-serum-plasma-guidelines.pdf (accessed on 1 November 2018).

91. Heneghan, H.M.; Miller, N.; Kerin, M.J. MiRNAs as biomarkers and therapeutic targets in cancer. Curr. Opin. Pharmacol. 2010, 10, 543-550. [CrossRef]

92. Bernstein, E.; Kim, S.Y.; Carmell, M.A.; Murchison, E.P.; Alcorn, H.; Li, M.Z.; Mills, A.A.; Elledge, S.J.; Anderson, K.V.; Hannon, G.J. Dicer is essential for mouse development. Nat. Genet. 2003, 35, $215-217$. [CrossRef]

93. Krützfeldt, J.; Rajewsky, N.; Braich, R.; Rajeev, K.G.; Tuschl, T.; Manoharan, M.; Stoffel, M. Silencing of microRNAs in vivo with 'antagomirs'. Nature 2005, 438, 685-689. [CrossRef] [PubMed]

94. Weiler, J.; Hunziker, J.; Hall, J. Anti-miRNA oligonucleotides (AMOs): Ammunition to target miRNAs implicated in human disease? Gene Ther. 2006, 13, 496-502. [CrossRef] [PubMed]

95. Croce, C.M. Causes and consequences of microRNA dysregulation in cancer. Nat. Rev. Genet. 2009, 10, 704-714. [CrossRef] [PubMed]

96. Visone, R.; Croce, C.M. MiRNAs and cancer. Am. J. Pathol. 2009, 174, 1131-1138. [CrossRef]

97. Iorio, M.V.; Croce, C.M. MicroRNAs in cancer: Small molecules with a huge impact. J. Clin. Oncol. 2009, 27, 5848-5856. [CrossRef] [PubMed]

98. Esquela-Kerscher, A.; Slack, F.J. Oncomirs-microRNAs with a role in cancer. Nat. Rev. Cancer 2006, 6, 259-269. [CrossRef] [PubMed]

99. Saumet, A.; Mathelier, A.; Lecellier, C.-H. The potential of MicroRNAs in personalized medicine against cancers. BioMed Res. Int. 2014, 2014, 642916. [CrossRef]

(C) 2019 by the authors. Licensee MDPI, Basel, Switzerland. This article is an open access article distributed under the terms and conditions of the Creative Commons Attribution (CC BY) license (http://creativecommons.org/licenses/by/4.0/). 